\title{
Analysis on the effects of folk dance training on players' spatial expectation levels
}

\author{
Kaya M. ${ }^{1 \mathrm{ABCDE}}$, Yilmaz A. ${ }^{2 \mathrm{ABCDE}}$ \\ ${ }^{1}$ School of Physical Education and Sports, Tokat Gaziosmanpaşa University, Turkey \\ ${ }^{2}$ Faculty of Sport Sciences, Erciyes University Kayseri, Turkey
}

Authors' Contribution: A - Study design; B - Data collection; C - Statistical analysis; D - Manuscript Preparation; E - Funds Collection.

\begin{tabular}{|c|c|}
\hline \multicolumn{2}{|l|}{ Abstract } \\
\hline Purpose: & $\begin{array}{l}\text { The purpose of this study was to investigate the effects on spatial perception and spatial anticipation levels } \\
\text { the effects of control and study groups with } 16 \text { week training folk dancing training. }\end{array}$ \\
\hline Material: & $\begin{array}{l}120 \text { voluntary college students with no folk dancing background, } 60 \text { of which is female has participated } \\
\text { in the study. The study group had folk dancing training of 16-week whereas control group has not done } \\
\text { any training. Brixton Spatial Expectations test was administered to control groups at the first, eighth and } \\
\text { sixteenth weeks of the training. Validation of which has previously been done "Prospects Brixton Spatial } \\
\text { Test" has been used in the study. A statistical analysis of the data obtained was done with available statistical } \\
\text { software (IBM SPSS Statistics 19, SPSS inc., An IBM Co., Somers, NY) and the significance level was taken as } \\
0.05 \text { and } 0.01 \text {. Similar results were obtained between experimental and control groups in this study. }\end{array}$ \\
\hline Results: & $\begin{array}{l}\text { There were not significant differences between groups in terms of measurement time as well as in gender. } \\
\text { As a result: Short-term training of folk dancing seems to have no impact on the level of spatial perception. }\end{array}$ \\
\hline Conclusions: & $\begin{array}{l}\text { To have a significant effect, a long-term folk dance training is required. In addition, level of spatial perception } \\
\text { on folk dance training has no significant difference in terms of gender. }\end{array}$ \\
\hline Ke & Turkish folk dances, spatial perception, brixton test, visual-spatial perception, physical activity. \\
\hline
\end{tabular}

\section{Introduction}

Folk dance as a concept is act and music integration supported with anonymous folk music that includes units of sound creating an aesthetic effect and excitement through the rhythmic and balanced figures as being organized in a euphonious way [1]. Turkish folk dances can be an important activity in terms of meeting the need for acting [2]. Within folk dances, there are exercises possible to develop the physical skills such as strength, balance, flexibility, and coordination. Turkish folk dance has a rich variety of figure diversity. Therefore, it can affect the physical characteristics of dancers and their abilities such as perception, interpretation and decision making depending on the speed of acting and the period [3]. One of the important aspects in folk dances includes staging, choreography, and orientation. Orientation in terms of folk dances is shortly defined as directing the dancers on the stage [4]. To achieve this, dancers are obliged to know all imaginary points and lines on the stage at different shapes. By the help of these points and lines, choreograph and easily establish contact with the dancers. Planning of the stage and determination of the orientation points organizes the acts of the dancers. So these provide dancers' reaching to the targets easily [5]. Staging trainings performed in folk dances also requires a mental study at the same time.

During the acting of the folk dances, dancers are obliged to control several factors at the same time. These factors include both physical and mental dimensions. Physically, the dancers are obliged to act the figures used during the dance in a balanced way appropriate to

(c) Kaya M., Yilmaz A., 2019

doi:10.15561/20755279.2019.0506 the property of the figure according to a specific order. Performing the figures at the same moment, transition from one dance to another or one figure to another, successful acting of the sections with high difficulty level during the dance depend all upon the physical skills of the dancers. All of the performed acts require a high level physical skill. Furthermore, dancers' acting in harmony with the music is also fairly important. Another dimension in acting of the folk dancers is folk dance's requiring a mental activity. When considered mentally, dancers are within two important activities while they are on stage. The first one is controlling the position on stage while thinking the figures and figure transitions and order of the figures (choreography order). And the second one is making place and direction predictions according to the choreography lines and the distance with the other dancers according to the dance and determining the position required to be on according to the orientation lines on the stage. The brain acts as a kind of synchronizer helping us to direct our moves, and providing the orientation of the body and harmony of the figures with the music. The situations such as jumping, leaping, balance and spatial awareness requires calculations in Sensorimotor system of the brain. [6]. All these reveal that folk dances reveal a mental process related to visual-spatial perception beside the physical activity in acting.

Visual-spatial perception is expressed as a way of perception changing according to the situation individuals are in. Spatial perception has a vital importance in organisms' providing adaptation to the environment and maintaining the presence $[7,8]$. Organisms react to the stimulus threating their presence and resources necessary for maintaining the presence perceiving the spatial 
location of both their own position and the spatial location of other living and non-living beings in a specific area [9].

Hypothesis: There are several factors requiring visual-spatial perception in the folk dances. In this sense, it is considered that folk dances can positively affect spatial perception. Purpose: The purpose of this study was to investigate the effects on spatial perception and spatial anticipation levels the effects of control and study groups with 16 week training folk dancing training.

\section{Material and Method}

Participants: Totally 120 university students including 60 female and 60 male studying at different departments of Gaziosmanpaşa University were included into this study.

The experimental groups included the students in different departments of Gaziosmanpaşa University. While choosing the students in this group, the students were regarded not to be participated into any folk dance trainings before. Experimental male group included 30 participants with $22.43 \pm 3.04$ age average, $172.43 \pm 4.07$ height average, and $68.03 \pm 6.05$ bodyweight average. And the experimental female group included 30 participants with $21.40 \pm 1.28$ age average, $164.87 \pm 4.45$ height average, and $59.23 \pm 9.18$ bodyweight average.

The control group participants included the students studying at Gaziosmanpaşa University, Vocational Health School. Control male group included 30 participants with $23.20 \pm 2.66$ age average, $173.47 \pm 4.73$ height average, and $68.03 \pm 6.05$ bodyweight average. And the control female group included 30 participants with $21.40 \pm 1.28$ age average, $164.87 \pm 4.45$ height average, and $69.40 \pm 8.80$ bodyweight average.

The research was approved by Gaziosmanpaşa University, Faculty of Medicine Ethical Committee on 12.12.2011. Furthermore, all volunteers who participated into the research were informed with consent form, and necessary permissions were taken from the relevant university.

Research Design: In the research, 16-week folk dance training program was prepared in order to implement to the experimental group. The trainings were worked out for 2-hour periods for 3 days in a week. During the first 8 weeks of the trainings, folk dances of Tokat local area were taught. After the ninth week, orientation and choreography trainings on the stage were performed. Especially during the on-stage trainings, orientation live and stage information were taught. Trainings of the experimental groups were worked out in sports hall of Gaziosmanpaşa University. No trainings were worked out with the control group. The volunteers in this group maintained their normal daily activities. Brixton Spatial Anticipation Test was performed to the volunteers in the experimental and control groups at the first, eighth, and sixteenth week of the trainings, and the results were recorded.

Brixton spatial anticipation test includes 55 pages and is performed manually. There are 10 circles including 5 at the top and 5 at the bottom on the pages. One of the circles on each page has blue color. These colored circles are listed in a specific system. According to this rule, position of the colored circle on each page changes. Tested individual is asked which numbered circle will be the blue colored circle on the other page. According to this, tested participant tries to make correct prediction. Wrong and correct answers are recorded as scores $[10,11]$.

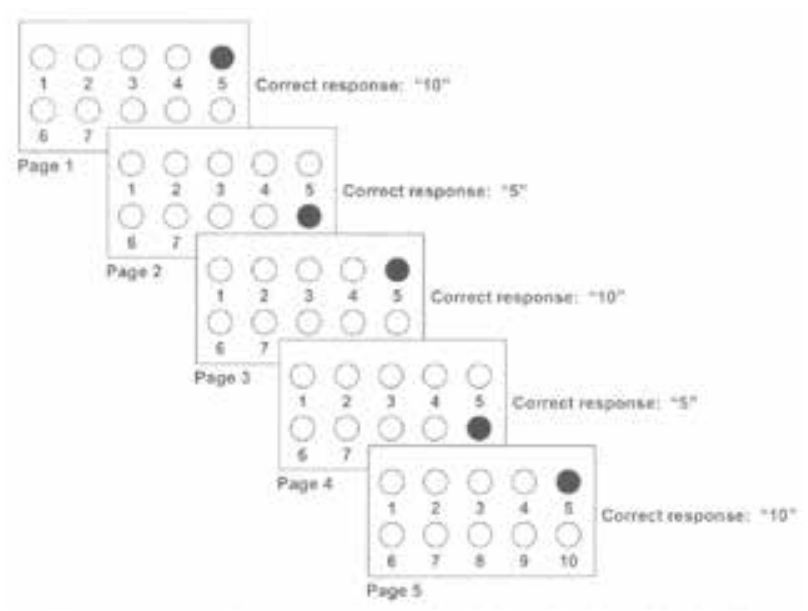

Fig. 1. Brixton Spatial Anticipation Test Order [12].

Statistical Analysis. For the comparison between the gender groups, significance test for the difference between the two averages was used. In situations when the number of the independent group was three and more, one-way variance analysis was used to compare the groups in terms of just one variable. After the significantly determined variance analysis, Tamhane's T2 test developed for the situations without homogenous distribution of the variances was used for the comparison. When there are repetitions on individuals, significance test between the two pairs was used. When calculated lower than 0.05 , it was accepted as statistically significant. The calculations were made using the ready statistical software (IBM SPSS Statistics 19, SPSS inc., an IBM Co., Somers, NY)

\section{Results}

In the comparison made between the first measurements of the female groups, no significant difference was found between the experimental female group and control female group. And in the comparison made between the first measurements of the male groups, no significant difference was also found between the experimental male group and control male group. No significant difference was found between the experimental female group and control female group in the comparison made between the second measurements of the female groups. Significant difference was not also found between the experimental male group and control male group in the comparison made between the second measurements of the male groups. Significant difference was found between the experimental female group and control female group in the comparison made between the third measurements 
Table 1. Intergroup Comparison of the Female and Male Groups in Terms of the First, Second and Third Measurement Variables

\begin{tabular}{|c|c|c|c|}
\hline \multicolumn{4}{|l|}{$1^{\text {st }}$ Measurement } \\
\hline Female Groups & $\mathrm{X} \pm \mathrm{SD}$ & $\mathbf{t}$ & $\mathbf{p}$ \\
\hline Experimental Female & $21.67 \pm 6.10$ & \multirow{2}{*}{1.080} & \multirow{2}{*}{0.284} \\
\hline Control Female & $23.40 \pm 6.32$ & & \\
\hline \multicolumn{4}{|l|}{ Male Groups } \\
\hline Experimental Male & $26.07 \pm 6.93$ & \multirow{2}{*}{1.472} & \multirow{2}{*}{0.159} \\
\hline Control Male & $23.83 \pm 5.04$ & & \\
\hline \multicolumn{4}{|l|}{$2^{\text {nd }}$ Measurement } \\
\hline Female Groups & $\mathrm{X} \pm \mathrm{SD}$ & $\mathbf{t}$ & $\mathbf{p}$ \\
\hline Experimental Female & $19.00 \pm 6.63$ & \multirow{2}{*}{1.958} & \multirow{2}{*}{0.055} \\
\hline Control Female & $22.00 \pm 5.14$ & & \\
\hline \multicolumn{4}{|l|}{ Male Groups } \\
\hline Experimental Male & $22.97 \pm 6.15$ & \multirow{2}{*}{0.568} & \multirow{2}{*}{0.572} \\
\hline Control Male & $22.20 \pm 4.10$ & & \\
\hline \multicolumn{4}{|l|}{$3^{\text {rd }}$ Measurement } \\
\hline Female Groups & $\mathrm{X} \pm \mathrm{SS}$ & $\mathbf{t}$ & $\mathbf{p}$ \\
\hline Experimental Female & $16.43 \pm 6.66$ & \multirow{2}{*}{2.599} & \multirow{2}{*}{$0.012 *$} \\
\hline Control Female & $20.30 \pm 4.70$ & & \\
\hline \multicolumn{4}{|l|}{ Male Groups } \\
\hline Experimental Male & $18.40 \pm 4.30$ & \multirow{2}{*}{0.854} & \multirow{2}{*}{0.397} \\
\hline Control Male & $19.23 \pm 3.18$ & & \\
\hline
\end{tabular}

*: Significance Test was used for the difference between two averages. The level of significance was accepted as 0.05 .

Table 2. Comparison of Experimental Female and Male Groups in Terms of Measurement Time

\begin{tabular}{|c|c|c|c|c|}
\hline Female Groups & $\mathbf{n}$ & $\mathrm{X} \pm$ SD & $t$ & $\mathbf{P}$ \\
\hline First measurement & 30 & $21.67 \pm 6.10$ & \multirow{3}{*}{3.508} & \multirow{3}{*}{$<0.001 *$} \\
\hline Second measurement & 30 & $19.00 \pm 6.63$ & & \\
\hline First measurement & 30 & $21.67 \pm 6.10$ & & \\
\hline Third measurement & 30 & $16.43 \pm 6.66$ & 6.295 & $<0.001^{*}$ \\
\hline Second measurement & 30 & $19.00 \pm 6.63$ & \multirow{2}{*}{4.074} & \multirow{2}{*}{$<0.001 *$} \\
\hline Third measurement & 30 & $16.43 \pm 6.66$ & & \\
\hline \multicolumn{5}{|l|}{ Male Groups } \\
\hline First measurement & 30 & $26.06 \pm 6.93$ & \multirow{2}{*}{4.206} & \multirow{3}{*}{$<0.001 *$} \\
\hline Second measurement & 30 & $22.96 \pm 6.15$ & & \\
\hline First measurement & 30 & $26.06 \pm 6.93$ & \multirow{2}{*}{6.737} & \\
\hline Third measurement & 30 & $18.40 \pm 4.29$ & & $<0.001 *$ \\
\hline Second measurement & 30 & $22.96 \pm 6.15$ & \multirow{2}{*}{4.758} & \multirow{2}{*}{$<0.001^{*}$} \\
\hline Third measurement & 30 & $18.40 \pm 4.29$ & & \\
\hline
\end{tabular}

*: Significance test for the difference between the two pairs was used. The level of significance was accepted as 0.05 .

of the female groups $(\mathrm{p}<0.05)$. In the comparison made between the second measurements of the male groups, no significant difference was found between the experimental male group and control male group.

As result of the comparisons made between the measurements of the experimental female groups, significant differences were determined between the first measurement and the second measurement, between the second measurement and the third measurement, and between the first measurement and third measurement $(p<0.05)$. And as result of the comparisons made between the measurements of the experimental male groups, significant differences were specified between the first measurement and the second measurement, between the second measurement and the third measurement, and between the first measurement and third measurement $(\mathrm{p}<0.05)$.

At the end of the comparisons made between the measurements of the control female groups, significant difference was determined between the first measurement and the second measurement $(p<0.05)$. Significant differences were also found between the second 
Table 3. Comparison of Control Female and Male Groups in Terms of Measurement Time

\begin{tabular}{|c|c|c|c|c|}
\hline Female Groups & $n$ & $X \pm S D$ & $t$ & $\mathbf{P}$ \\
\hline First measurement & 30 & $23.40 \pm 6.32$ & \multirow{2}{*}{2.132} & \multirow{2}{*}{$0.042 *$} \\
\hline Second measurement & 30 & $22.00 \pm 5.13$ & & \\
\hline First measurement & 30 & $23.40 \pm 6.32$ & \multirow{2}{*}{3.932} & \multirow{2}{*}{$<0.001^{*}$} \\
\hline Third measurement & 30 & $20.30 \pm 4.69$ & & \\
\hline Second measurement & 30 & $22.00 \pm 5.13$ & \multirow{2}{*}{4.378} & \multirow{2}{*}{$<0.001 *$} \\
\hline Third measurement & 30 & $20.30 \pm 4.69$ & & \\
\hline \multicolumn{5}{|l|}{ Male Groups } \\
\hline First measurement & 30 & $23.83 \pm 5.03$ & \multirow{2}{*}{4.242} & \multirow{2}{*}{$<0.001^{*}$} \\
\hline Second measurement & 30 & $22.20 \pm 4.09$ & & \\
\hline First measurement & 30 & $23.83 \pm 5.03$ & \multirow{2}{*}{9.472} & \multirow{2}{*}{$<0.001 *$} \\
\hline Third measurement & 30 & $19.23 \pm 3.18$ & & \\
\hline Second measurement & 30 & $22.20 \pm 4.09$ & \multirow{2}{*}{8.383} & \multirow{2}{*}{$<0.001^{*}$} \\
\hline Third measurement & 30 & $19.23 \pm 3.18$ & & \\
\hline
\end{tabular}

*: Significance test for the difference between the two pairs was used. The level of significance was accepted as 0.05 .

Table 4. Comparison of Number of Errors According to the Measurements of the Groups in Terms of Gender

\begin{tabular}{llllll}
\hline Groups & Gender & $\mathbf{n}$ & $\mathbf{X} \pm$ SD & t & P \\
\hline \multirow{2}{*}{ First measurement } & Female & 90 & $19.30 \pm 6.98$ & 0.606 & 0.545 \\
& Male & 90 & $20.01 \pm 8.67$ & & 0.848 \\
Second measurement & Female & 90 & $17.48 \pm 6.66$ & & 0.397 \\
& Male & 90 & $18.37 \pm 7.38$ & 0.112 & 0.911 \\
\hline
\end{tabular}

*: Significance test for the difference between the two pairs was used. The level of significance was accepted as 0.05 .

measurement and the third measurement, and the first measurement and third measurement $(\mathrm{p}<0.05)$. As result of the comparisons made between the measurements of the control male groups, significant differences were proved between the first measurement and the second measurement, second measurement and the third measurement, and first measurement and the third measurement $(p<0,05)$.

In comparison of the groups' error averages, no significant difference was determined between the female groups and male groups according to the first, second and third measurements in terms of gender.

\section{Discussion}

When folk dances are considered in terms of their acting properties apart from their social and cultural properties, these can be noticed to have a very rich acting structure. It is certain that folk dance trainings performed regularly and systematically have effects at different dimensions on the organism [13]. The reason for these effects is the training programs worked out heavily before the staging performance of the folk dances. Because there are limited number of studies carried out upon how folk dance trainings can affect the dancers physically, physiologically, and mentally, it is hard to obtain concrete data.
In literature review, it was determined that there were no studies at national or international levels related to "spatial perception and spatial anticipation in folk dancers." The mental dimension of folk dances is an important topic to be investigated. In reference to this point, this study was carried out in order to make a clarification for the literature primarily. In this sense, our research was completely original, and will make significant contributions for the subsequent studies on the same topic. Furthermore, because there were limited number of scientific studies related to this topic, the comparisons were made with the researches carried out upon the same quality but in different sports branches.

According to the data obtained from the research, it was noticed when general total error averages of the groups was considered that experimental and control group error averages in all three measurements and error averages of the female and male groups were in parallel with each other.

When the comparison results made between measurement period intervals of the female and male groups (experimental and control groups) were analyzed, differences were determined between the first measurement and second measurement, second measurement and the third measurement, and the first measurement and the third measurement. Paired comparison results between the first, 
second and third measurements of the experimental and control groups were not parallel to our expectations. In order to say that 16-week training period had effect upon the experimental groups, it was necessary to have a change in the control groups. Obtaining similar results in both of the control and experimental groups revealed the view that long-term folk dance trainings did not affect spatial anticipation level in dancers. And this was considered to be arisen from awareness levels' being affected due to the short interval between the measurements. Namely, it was regarded that the volunteers high possibly remembered the measurement order of the previous test between the measurements. In order for the awareness level not to have an effect, the period between the measurements was considered to be kept longer.

In a research carried out by Memmert et al., the relationship between visual attention and expertness of 40 (20 Female 20 Male) senior handball players with 24 age average and 10 sports age and 40 (20 Female 20 Male) junior handball players with 25 age average and 2 sports age was compared. In the research, it was concluded that visual attention of the senior handball players was better rather than the visual attention of the junior players [14].

In a study carried out by Jansen and Lehmann, spatial cognition level of the football players was investigated. Into the study, totally 40 volunteer university students including 20 football players and 20 sedentary with 24 age average participated. Mental rotation test was performed to the volunteers through computer software. It was found in obtained findings that football players had better spatial cognition levels rather than the ones who did not play football. In the same study, mental rotation levels of totally 40 gymnasts including 20 female and 20 male with 23 age average were investigated, and it was concluded that the gymnasts had better mental rotation levels rather than the non-gymnast ones [15].

In a research carried out by Özel et al., the relationship between sporting and spatial perception of Physical Education and Sports department students was investigated. It was found in the study that mental rotation properties of the sportsmen were better rather than the others. Moreover, mental rotation levels of the sportsmen playing in open skill-based sports branches such as basketball, football, badminton, wrestling, judo and table tennis were determined to be better than the mental rotation levels of the sportsmen playing in closed skill-based sports branches such as cycling, swimming, archery, and javelin throw. And general mental rotation properties were observed to be increased after long-term sportive activities [16].

In their research, Somon and Hassam investigated the effect of mental image training upon the skills and performances of football players at different levels. In the study, the image use scale developed by Hall, Rodgers and Barr was used. It was found in the research that there was an increase at motivation and performances of the 362 football players trained with mental imaging. Furthermore, it was revealed that image use levels of the elite football players were better rather than the image use levels of the non-elite football players [17]. According to the data obtained in these studies, mental imaging and mental rotation properties of the expert sportsmen were noticed to be better rather than the individuals not doing sports. Folk dance trainings worked out for a short period were considered as not being efficient upon the spatial perception levels of the dancers.

In the studies investigating the relationship between the spatial ability and gender, various and conflicting results were obtained. Whereas performance of the males was determined to be higher in some studies, no difference between the genders was concluded in the others. Different evaluations were made related to these obtained conflicting results [18].

Whereas Okagaki and Frensch found difference in favor of males in complex mental rotation tasks, no gender difference was found in mental rotation measurement performed with the shapes used in Tetris game at a simple level. Similarly, no gender difference was determined in computerized spatial imaging tasks [19].

Kaufman investigated whether the gender difference in mental rotation and spatial imaging abilities was valid for the running memory or not. In the research, difference according to the gender was obtained in terms of spatial imaging and mental rotation abilities [20].

Nemeth and Hoffman investigated success and gender relationship in terms of the Engineering faculty students using Mental Cutting Test (MCT). A significant difference was obtained in favor of the male students in the study [21].

In their research, Subrahmanyan and Greenfield analyzed the effect of gender upon the spatial abilities of the group including 28 male and 33 female. Performance of the males was found to be higher rather than the females in the beginning, and at the end of the study, males were determined to be more successful [22].

In their research, Hromatko and Butkovic performed spatial relationships and mental rotation test to 201 university students with 28 age average. In the study, a difference was determined in terms of the gender, and spatial abilities of the male students were higher rather than the spatial abilities of the female students [23].

In the research, Y1ldiz performed "Spatial Visualization Test" and "Mental Rotation Test" to the group including 56 females and 52 males. According to the obtained data, no significant difference was found in terms of the gender according to "Spatial Visualization Test" and "Mental Rotation Test" performances [18].

In their research, Linn and Petersen investigated the categorization of spatial abilities in terms of the gender differences. According to the research results, they found that there was no difference between the genders in the same age categories [24]. These researches supported the data we obtained in our study.

In the studies carried out upon the spatial abilities, it could be noticed that there were various and conflicting results related to the gender difference, and these results were associated with the various reasons. Using different age groups and different measurement tools 
could be efficient upon obtaining these different results. In this study, when the comparisons between the three measurements in terms of general group and gender factor were investigated, no difference was specified between the change at time levels and genders. Having no difference between the genders in terms of time levels was a parallel result to ours.

\section{Conclusion.}

The results of this study proved that mental dimensions of the 16-week folk dance trainings were noticed to have no effect on spatial anticipation levels of the folk dancers.
It was considered that long-term folk dance trainings should be worked out in order to have an effect. Furthermore, folk dance trainings affected spatial perception and spatial anticipation at the same level in terms of gender; namely, there was no difference in terms of female and male folk dancers.

\section{Conflict of interest.}

The authors state that there is no conflict of interest.

\section{References}

1. Ekmekcioğlu İ, Bekar C, Kaplan M. Turkish Folk Dances. İstanbul: Esin Press; 2001.

2. Gerek Z. Comparison of Physical Fitness of Folk Dances and Sport Educated University Students By EUROFIT [Unpublished Doctoral Dissertation]. Ankara: Gazi University Institute of Health Sciences; 2007.

3. Ünveren A. The Effects of Regular Folk Dance Studies on Selected Physical and Physiological Parameters of University Students [Master Thesis]. Elazı $\breve{g}$ : Firat University, Institute of Health Sciences; 1997.

4. Pınar S, Atılgan O E, Tavlacioğlu L. Evaluation of GenderRelated Differences in Demonstrating Equilibrium Skill in Adult Dancers. 9th International Congress on Sport Sciences, Book of Proceedings, Muğla University. 2006. P.296-298.

5. Koçkar MT. Dance and Folk Dances. Ankara: Bağırgan Press; 1998.

6. Brown S, Parsons LM. The Neuroscience of Dance. Scientific American, 2008;299:78-83. https://doi.org/10.1038/scientificamerican0708-78

7. Kurt M. Cognitive Functions of Right Hemisphere: VisualSpatial Processes, Cognitive Neuroscience Chapter 8, Ankara: Medical and Nobel Medical Bookstore; 2010.

8. Karakaş S, İrkeç C, Yüksel N. Brain and Neuropsychology Basic Clinical Sciences, Ankara: Çizgi Press; 2003.

9. Kurt M. Components of Visual-Spatial Capabilities. 38th National Psychiatry Congress, 22 - 27 October 2002, Marmaris; 2002. P. 100-116.

10.Gohier B, Ferracci L, Surguladze SA, Lawrence E, El Hage W, Kefi MZ, et al. Cognitive inhibition and working memory in unipolar depression. Journal of Affective Disorders, 2009;116:100-105 https://doi.org/10.1016/j.jad.2008.10.028

11.Bayliss DM, Roodenrys S. Executive Processing and Attention Deficit Hyperactivity Disorder: An Application of the Supervisory Attentional System. Developmental Neuropsychology, 2000; 17(2): 161-180. https://doi.org/10.1207/S15326942DN1702 02

12.Bielak AAM, Mansueti L, Strauss E, Dixon RA. Performance on the Hayling and Brixton Tests in Older Adults: Norms and Correlates. Archives of Clinical Neuropsychology, 2006; 2: 141-149. https://doi.org/10.1016/j.acn.2005.08.006

13.Ünveren A. Determination of Physical Activity Level of Turkish Folk Dances. [Ph.D. Thesis]. Gazi University Institute of Health Sciences; 2005.
14.Daniel Memmert, Daniel J. Simons B. Thorsten Grimm, The Relationship Between Visual Attention And Expertise in Sports. Psychology of Sport and Exercise, 2009; 10: 146-156. https://doi.org/10.1016/j.psychsport.2008.06.002

15.Jansen P, Lehmann J. Mental Rotation performance in Soccer Players And Gymnasts in an Object-Based Mental Rotation Task. Advances Cognitıve Psychology, 2013; 9 (2): 92-98. https://doi.org/10.5709/acp-0135-8

16.Ozel S, Larue J, Molinaro C. Relation Between Sport and Spatial Imagery: Comparison of Three Groups of Participants. The Journal of Psychology, 2004;138:49-64. https://doi.org/10.3200/JRLP.138.1.49-64

17.Solmon J, Hall C, Haslam I. The Use of İmagery By Soccer Players. Joumal of Applied Sport Psychology. 1994; 6 (1): 116-133. https://doi.org/10.1080/10413209408406469

18.Yild1z B, The Effects of Three-Dimensional Virtual Environment and Concrete Use on Spatial Visualization and Mental Rotation Skills [Master Thesis]. Ankara: Hacettepe University, Institute of Science and Technology; 2009.

19.Okagaki LR, Frensch PA. Effects of Video Game Playing on Measures of Spatial Performance: Gender Effects in Late Adolescents. In: P. Greenfield \& R. Cocking (Eds.), Interacting With Norwood, NJ: Ablex Corporation Vide; 1996. P.115-140.

20.Kaufman SB. Sex Differences in Mental Rotation And Spatial Visualisation Ability: Can They be Accounted For by Differences in Working Memory Capacity? Intelligence, 2006; 35: 211-223. https://doi.org/10.1016/j.intell.2006.07.009.

21.Nemeth B, Hoffman M. Gender Differences in Spatial Visualisation Among Engineering Students. Annales Mathematicae et Informaticae, 2006; 33: 169-174.

22.Subrahmanyan K, Greenfield PM. Effects of Video Game Practice on Spatial Skills in Girls And Boys. In P. Greenfield R. Cocking (Eds.) Interacting With Video Norwood, NJ: Ablex Corporation; 1996. P. 94 -114.

23.Hromatko I, Butkovic A. Sensation Seeking And Spatial Ability in Athletes: an Evolutionary Account. Journal of Human Kinetics, 2009; 21: 21-13. https://doi.org/10.2478/v10078-09-0001-x

24.Linn MC, Petersen AC. Emergence and Characterization of Sex Differences in Spatial Ability: A Meta-Analysis. Child Development 1985;56:1479. https://doi.org/10.2307/1130467 
Information about the authors:

Kaya M.; http://orcid.org/0000-0002-8158-4671; efe588@hotmail.com; School of Physical Education and Sports, Tokat Gaziosmanpaşa University; 60200, Tokat, Turkey.

Yilmaz A.; (Corresponding Author); http://orcid.org/0000-0002-3563-0403; yilmaz@erciyes.edu.tr; Faculty of Sport Sciences, Erciyes University ; 38090, Kayseri, Turkey.

\section{Cite this article as:}

Kaya M, Yilmaz A. Analysis on the effects of folk dance training on players' spatial expectation levels. Physical education of students, 2019;23(5):249-255.

https://doi.org/10.15561/20755279.2019.0506

This is an Open Access article distributed under the terms of the Creative Commons Attribution License, which permits unrestricted use, distribution, and reproduction in any medium, provided the original work is properly cited http://creativecommons.org/licenses/by/4.0/deed.en

Received: 13.09 .2019

Accepted: 17.10.2019; Published: 26.10.2019 